\title{
Mortalidade por Causas Evitáveis, Municípios de Lins e Penápolis, Estado de São Paulo,
}

\section{9-81 e 1990-92.}

Valéria Vernachi Lima*

No Brasil, as políticas de saúde implementadas desde o início dos anos 70 , refletiram uma crescente intervenção estatal, acentuando algumas tendências em direção à privatização de serviços de saúde e hipertrofia da máquina administrativa dos aparelhos institucionais, com grande concentração de recursos.

No final dos anos 70, este modelo mostrava enormes inadequações à realidade sanitária brasileira e não conseguia alterar o perfil de mortalidade, no qual persistiam doenças facilmente evitáveis com medidas de caráter preventivo.

Acrescentam-se a este panorama os crescentes custos da atenção médica, a incorporação descontrolada de tecnologia e a ausência de critérios para a compra de serviços privados, levando à inviabilização da expansão de cobertura e uma crise no setor.

As Ações Integradas de Saúde (1985) e o Sistema Unificado e Descentralizado de Saúde foram tentativas do Estado para reorganizar os serviços, ampliar cobertura e (1987) descentralizar a gestão dos mesmos.

Atualmente o Sistema Único de Saúde, garantido pela constituição de 1988, encontra enormes dificuldades para viabilizar-se, tendo na crise financeira do Estado Brasileiro o principal obstáculo para a manutenção do direito universal à saúde, eqüidade de acesso e gratuidade dos serviços.

\footnotetext{
* Mestre em Saúde Pública, consultora da Faculdade de Medicina de Marília e da Fundação SEADE.
} 
No Estado de São Paulo, as experiências de descentralização políticoadministrativa do Sistema de Saúde constituíram-se, com o Sistema Unificado e Descentralizado de Saúde, em 1987, numa diretriz governamental para o setor.

A municipalização dos serviços de saúde passou a ser a estratégia de efetivação desta descentralização pretendida. Através de convênios, os municípios passaram a gerenciar os serviços públicos de saúde e a operacionalizar políticas locais de saúde.

De fato, a municipalização da saúde encontrou grandes diversidades na capacidade administrativa gerencial dos municípios e na atuação das estruturas regionalizadas da Secretaria Estadual de Saúde. Embora a municipalização da saúde não seja em si mesma a solução para o paradigma do modelo assistencial ou tampouco do processo de descentralização, apresentou-se como uma oportunidade ímpar para a experimentação de propostas transformadoras em direção às necessidades de saúde da população e à viabilização do Sistema Único de Saúde.

Este trabalho pretendeu avaliar a experiência de dois municípios no interior do Estado de São Paulo, Lins e Penápolis, tomando-se dois períodos, 1979-81 e 1990-92. O município de Penápolis teve seus serviços de saúde municipalizados em 1987 e Lins apenas em final de 1992. O indicador utilizado para comparar resultados das experiências destes dois municípios foi a mortalidade evitável.

\section{Mortalidade Evitável}

A mortalidade evitável é considerada um evento sentinela para os Sistemas de Saúde.

RUTSTEIN ${ }^{(1)}$ classificou as mortes evitáveis segundo a quantidade de casos esperados para determinados grupos de doença. No grupo A estão aquelas causas para as quais um só caso indica a presença de evento sentinela. $\mathrm{O}$ grupo B é aquele para o qual uma determinada taxa das causas de óbito indica a presença do evento. TAUCHER ${ }^{(2)}$ classificou as causas de morte evitáveis segundo o tipo de intervenção que os serviços de saúde são capazes de produzir para evitar as mortes.

Este trabalho utilizou o conceito de evento sentinela e a classificação de E. Taucher, ampliando-a e adaptando-a à realidade epidemiológica brasileira.

Foram utilizados 4 grupos de causas evitáveis sendo:

- Evitáveis I - por vacinação e tratamento preventivo;

- Evitáveis II - por diagnóstico precoce e tratamento oportuno;

- Evitáveis III - por medidas de saneamento, higiene e educação sanitária;

- Evitáveis IV - por medidas mistas; 
- Dificilmente evitavéis;

- Sinais e sintomas mal definidos e

- Outros.

Para análise estatística utilizou-se apenas as causas evitáveis e dificilmente evitáveis e aplicou-se a teste $\mathrm{x}^{2}$ de associação. Os óbitos foram estatificados segundo grupos de idade ( 0 a 4,5 a 14, 15 a 49, 50 a 69 e maiores de 69 anos), para os municípios e períodos.

\section{Resultados}

Os dois municípios têm populações e base sócio econômica semelhantes. Distam entre si apenas $50 \mathrm{Km}$ e têm sua base econômica vinculada a monocultura de cana de açúcar, pecuário e atividades secundárias relacionadas ao processamento dos produtos agropecuários (agroindústria). A tabela 1 mostra algumas destas características.

Tabela 1 - Características dos municípios de Lins e Penápolis, 1980 e 1991.

\begin{tabular}{lrrrr}
\hline & \multicolumn{2}{c}{ Lins } & \multicolumn{2}{c}{ Penápolis } \\
& 1980 & 1991 & 1980 & 1991 \\
\hline População & 50902 & 59098 & 40207 & 47972 \\
Receita Munic. & US 1675 & US 2657 & US 1422 & US 3276 \\
$\begin{array}{l}\text { Cob. água } \\
\text { Cob. Esgoto }\end{array}$ & - & $98 \%$ & $69,7 \%$ & $99,5 \%$ \\
$\begin{array}{l}\text { População } \\
\text { com renda }\end{array}$ & - & $90 \%$ & $54,6 \%$ & $97,7 \%$ \\
até 2 SM & $66 \%$ & - & & \\
\hline
\end{tabular}

Fonte: Fundação SEADE.

Observou-se em relação aos serviços de saúde em Penápolis uma importante presença pública e grande incremento de cobertura no período estudado. $\mathrm{O}$ município de Lins por ser sede de uma região de governo já apresentava em 1980 um maior oferta de serviços em relação à Penápolis. A presença da iniciativa privada em Lins é notadamente mais expressiva.

A tabela 2 apresenta algumas características dos serviços de saúde nos dois municípios estudados. 
Tabela 2 - Características dos serviços de saúde, municípios de Lins e Penápolis, 1980 e 1991.

\begin{tabular}{lcccc}
\hline & \multicolumn{2}{c}{ Lins } & \multicolumn{2}{c}{ Penápolis } \\
& 1980 & 1991 & 1980 & 1991 \\
\hline $\begin{array}{l}\text { no médicos/mil } \\
\text { habitantes } \\
\text { prof. de saúde/ } \\
\text { mil habitantes } \\
\text { percentual do }\end{array}$ & 1,04 & 1,31 & 1,04 & 1,06 \\
$\begin{array}{l}\text { orçamento para } \\
\text { saúde }\end{array}$ & 0,77 & 2,07 & 0,68 & 4,25 \\
$\begin{array}{l}\text { produção de } \\
\text { cons. médica }\end{array}$ & $2,6 \%$ & $2,8 \%$ & & \\
$\begin{array}{l}\text { leitos/mil } \\
\text { habitantes }\end{array}$ & - & 179.104 & 6234 & 134.073 \\
\hline
\end{tabular}

Fontes: Prefeituras Municipais de Lins e Penápolis

A mortalidade evitável em Lins e Penápolis, segundo grupo de evitabilidade, pode ser observada, para os dois períodos, na tabela 3 .

Tabela 3 - Números de óbitos e porcentagem dos totais, segundo grupos de evitabilidade, Lins e Penápolis, 1979-81 e 1990-92.

\begin{tabular}{lrrrr}
\hline & \multicolumn{2}{c}{ Lins } & \multicolumn{2}{c}{ Penápolis } \\
& $1979-81$ & $1990-92$ & $1979-81$ & $1990-92$ \\
\hline \multirow{2}{*}{ Evitáveis I } & 6 & 4 & 5 & 2 \\
Evitáveis II & 106 & 118 & 92 & 88 \\
Evitáveis III & 46 & 9 & 26 & 6 \\
Evitáveis IV & 280 & 345 & 228 & 236 \\
& & & & \\
\hline Subtotal & $438(42,7 \%)$ & $476(41,6 \%)$ & $351(46,3 \%)$ & $332(40,4 \%)$ \\
\hline Dif. Evitáveis & $588(57,3 \%)$ & $669(58,4 \%)$ & $406(53,7 \%)$ & $490(56,6 \%)$ \\
\hline Total & $1026(100,0 \%)$ & $1145(100,0 \%)$ & $757(100,0 \%)$ & $822(100,0 \%)$ \\
\hline
\end{tabular}


Os óbitos foram distribuídos pelos grupos de idade já definidos e aplicouse o teste a associação de Mantel-Haenszel. Fixado o período, para óbitos evitáveis e dificilmente evitáveis, entre Lins e Penápolis, houve associação positiva e estatisticamente significante, em 1979-81, para Penápolis e óbitos evitáveis.

Em 1990-92, o teste não foi estatisticamente significativo.

Fixando-se os municípios, para Lins, entre os períodos estudados, encontrou-se associação positiva, e estatisticamente significante entre óbitos evitáveis e 1990-92.

Para Penápolis não houve diferença estatisticamente significante entre os períodos. Entretanto, para os dois municípios, a análise estatística da distribuição dos óbitos evitáveis, segundo grupos de intervenção, entre 1979-81 e 1990-92, mostrou diferenças estatisticamente significantes.

A análise temporal dos coeficientes padronizados de mortalidade, para os grupos de causas evitáveis, mostra queda em todos os grupos, para Lins e Penápolis. Porém o teste de associação de Mantel-Haenszel, estratificado segundo faixa etária, somente apresentou significância estatística para o grupo III (evitáveis por saneamento básico, higiene e educação) tanto para Lins como em Penápolis. Para os grupos II (evitáveis por diagnóstico e tratamento preventivo) e IV (evitáveis por medidas mistas) o teste foi significativo apenas para Penápolis. A análise estatística das diferenças da mortalidade, entre os municípios, não foi significante para nenhum grupo de causas evitáveis.

\section{Comentários}

A maior cobertura, acessibilidade e resolubilidade dos serviços de Penápolis em 1990-92, foram os aspectos ligados a serviços de saúde que potencialmente contribuíram para as quedas da mortalidade dos grupos II, III e IV.

\section{Referências Bibliográficas}

1. RUTSTEIN, D. D. et al. Measuring the quality of medical care. $N$. Engl. J. Med., 294:582 - 8, 1976.

2. TAUCHER, E. Chile: Mortalidade desde 1955 a 1975, tendencias y causas Santiago, Celade, 1978. (CELADE, Série A, 162) 